\title{
Row over industry link-up splits staff of Spanish lab
}

Madrid. Three scientific directors and a deputy director have resigned their posts at the National Biotechnology Centre (CNB) in Madrid over the terms of an agreement under which laboratory space at the centre will be rented to Pharmacia Iberia, the Spanish subsidiary of the Swedish pharmaceutical company Pharmacia.

The centre belongs to Spain's Consejo Superior de Investigaciones Cientificas (CSIC), and the agreement has opened a fierce debate on collaboration between the private sector and public research centres in Spain.

According to the seven-year agreement - which has yet to be ratified by Pharmacia's headquarters - Pharmacia Iberia will equip laboratories on one floor of CNB's four-floor building. It will also set up a joint research department in immunology and oncology with a research staff from both Pharmacia and CNB.

The overall deal is worth Pta 8 billion (US\$60 million).

Equipping the laboratories will cost Pta 450 million, and the rest of the money will pay for the salaries of Pharmacia Iberia's research staff, and about 25 per cent of the general running costs of $\mathrm{CNB}$.

In exchange, all patent rights on research carried out in the Pharmacia-CNB laboratory will belong to the company. According to the agreement CNB will be offered compensation "to be negotiated in good faith".

CSIC, whose budget has been frozen for five years (funding for the new centre ran out before its final floor could be fitted), has encouraged collaboration between public research centres and private industry both as a way of increasing research funding and of developing more market-orientated science and technology projects.

Many collaborative projects have been agreed. But that with Pharmacia Iberia is the first under which CSIC laboratories have been rented out and at the same time all intellectual property rights have been given to a private company.

José Mato, the president of CSIC, sees the Pharmacia Iberia agreement as a model for the future. "It is an innovative contract", he says. "We are taking some risks, but there are increased benefits, such as increasing interchange between basic research and technological development."

Such views are strongly endorsed by the new secretary of state for universities and research, Emilio Octavio de Toledo. He describes the agreement as a "well-balanced collaboration, the most important yet be- tween CSIC and industry."

But many CSIC scientists are angry at what they feel to be industry's exploitation of a public institute, claiming that CSIC has given away too much to Pharmacia Iberia. Angel Pestaña, for example, who represents CSIC researchers on its governing board, says the agreement "does not conform to the normal formula to regulate collaboration among scientific institutions".

CSIC staff are also upset that neither the

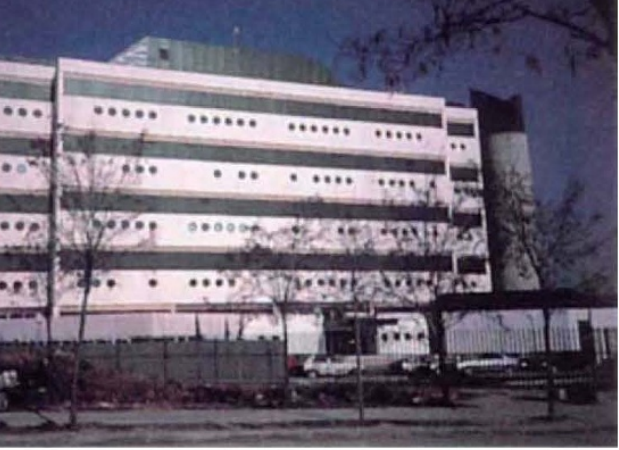

head of the CNB nor its four scientific directors were consulted before the deal was made public at the beginning of October.

José Luis Carrascosa, one of the four scientists who resigned their administrative posts over the affair (although continuing to work as researchers at the institute), says that $\mathrm{CSIC}$ has reneged on a written promise to consult $\mathrm{CNB}$ before anything was signed.

Scientists are worried that Pharmacia Iberia may use the agreement as an excuse to close down its own industrial research and development centre.

There is a precedent. Pharmacia Iberia was formed in May 1993, when KABIPharmacia merged with the company Farmitalia Carlo Erba. A month before the merger, $\mathrm{KABI}$ and $\mathrm{CSIC}$ signed an agreement to set up an immunology unit at CNB, made up of both KABI and CSIC staff.

The agreement itself was not controversial. But shortly afterwards KABI closed its own research centre Instituto Llorente and dismissed half of its staff. Carlos Laró, a spokesman for Pharmacia Iberia, concedes that this agreement "re-orientated a line of research in immunology that we then discontinued at Llorente".

Laro adds that the company has not made an official decision on the future of its own R\&D centre Antibióticos Farma. "We will have to coordinate their work with our work at CNB," he says. In his view, the deal is a positive one for CSIC, as "otherwise the floor at CNB would have remained empty". Luis-Angel Fernandez Hermana

\section{CNRS agrees to pay up over destruction of computer files}

Paris. A French physicist has won a second legal round against the Centre National de la Recherche Scientifique (CNRS) in a sevenyear fight to contest the way that the CNRS stripped him of his research funding and expelled him from its Nice observatory without any formal disciplinary procedure.

Gilbert Reinisch and his colleague JeanClaude Fernandez were expelled in 1987 by Raymond Michard, then director of the observatory. Both immediately filed a lawsuit, and Philippe Delache, Michard's successor, reinstated he researchers, but working next to astronomers and not in their physics laboratory.

The conflict might have stopped there, but Michard also ordered the closure of the researchers' accounts at the super-computer centre at Montpellier without informing them. The files were subsequently destroyed; Reinisch claims they included software developed as part of a collaborative European Union research programme.

CNRS launched an internal investigation into the matter, which found in favour of the laboratory management. Moreover, Delache wrote to the director general of CNRS that "study of the report leads me to conclude that these researchers have no place in my establishment". In December 1990, he ordered both researchers to leave the observatory within two weeks.

Reinisch and Fernandez were subsequently sent to share an unequipped room in a geology institute $20 \mathrm{~km}$ away. Later in 1991 , the administrative tribunal of Nice ruled that Michard's initial expulsion of the researchers had been an abuse of power and should be revoked. But CNRS has never reinstated the researchers.

In the latest twist, the same tribunal last month ruled that CNRS was responsible for the destruction of the computer files, and ordered the agency to pay each of the researchers FFr15,000 (US\$2,800) for damage to their scientific reputation.

Reinisch condemns the fact that it has been left to him to prove improper treatment by CNRS, claiming that the years of legal procedures have irreparably damaged his career and reputation. The CNRS, for its part, admits that "there was an administrative mistake," but says that it is not in proportion to Reinisch's claim, and that the judgement "does not directly condemn the CNRS."

The final verdict will come next year, when the tribunal rules on the legality of the expulsion of the researchers, following the dispute over the computer files. Meanwhile, Reinisch has written to Guy Aubert, the newly appointed director general of CNRS, asking him to close the dispute and reinstate him and his colleague.
Declan Butler 